\title{
BROAD-WINGED HAWK KETTLES IN BRANDON
}

\author{
JEAN HORTON, 3265 Rosser Avenue, Brandon, Manitoba. R7B 0H1
}

On the morning of 22 September 1986, six medium-sized chunky hawks were observed in Brandon's west end in an area where they are not generally observed. Upon obtaining binoculars $(7 \times 35$ and 10 $x 24)$ to aid in positive identification, a group of seventeen hawks was observed and identified as Broad-winged Hawks. Several hawks flew directly overhead and two white and two black bands in the tail were clearly observed. Sighting distances varied from very close to approximately $0.75 \mathrm{mi}$. Observation continued from the deck of a residential home overlooking the Assiniboine Valley, and during a one hour period the following kettles of Broadwinged Hawks were observed:

\section{Time}

Number of Hawks

\section{7}

30 travelled se but it was impossible to see if they continued to follow the river.

Weather conditions at the time were recorded as $10^{\circ} \mathrm{C}$ with wind from the west at 10 knots (about $18 \mathrm{kmph}$ ) with good visibility and intermittent sunny periods.

Details of the Brandon sighting were reported to Cal Cuthbert, one of Brandon's most experienced and expert birders, who reported seeing a Broad-winged Hawk that morning in an area where he had not seen one previously.

It is interesting to note that the 22 September observation date is consistent with information on Broad-winged Hawk flights in Ontario and the United States, which are said to peak during the middle of September and often contain thousands of hawks between 11 and 24 September. ${ }^{12}$

1 HEINTZELMAN, DONALD S. 1982. A guide to Hawk Watching in North America. The Pennsylvania State Univ. Press.

${ }^{2}$ GODFREY, W.E. 1966. The Birds of Canada. National Museum of Canada, Ottawa.

\section{TOTAL}

The total observed was 106 Broadwinged Hawks in a 1 hour period. Each small group of hawks appeared to be repeatedly sailing upwards on thermals and then gliding down to new thermals in a se direction. Because of the high density of houses in the area it was not possible to see the flight path of the hawks for a long distance. It appeared that they crossed the Assiniboine River and 